\title{
Nursing Interventions: Effects of Coma Arousal Technique on the Clinical Outcomes of Unconscious Patients
}

\author{
Hanan Mohammed Mohammed ${ }^{1}$, Abeer El-Said Hassane ${ }^{2}$ \\ ${ }^{1}$ Assistant Professor of Medical-Surgical Nursing Department, Faculty of Nursing, \\ Ain Shams University, Egypt \\ ${ }^{2}$ Lecturer of Medical-Surgical Nursing, Medical Surgical Department, Faculty of Nursing \\ Menoufia University, Egypt
}

\begin{abstract}
Unconsciousness is a condition of being unaware of one's surroundings as in sleep or of being unresponsive to stimulation. Therefore, to facilitate the recovery process, coma arousal technique has been developed. The present study aimed to evaluate the effect of coma arousal technique on clinical outcomes of unconscious patients.

Study design: A quasi-experimental design was utilized.

Study setting: Neuro, chest and medicine intensive care units at Ain -Shams University Specialized Hospital. Study sample: The purposeful sampling of sixty patients were randomly and alternatively divided into two equal groups (study\& control),30 subjects each.

Tool of data collection: Demographic and clinical data Sheet, Physiological parameters adverse events assessment, Rappaport coma (RCS), Motor Activity Assessment (MAAS) and Sensory Modality Assessment and Rehabilitation Technique (SMART) were used.

Results: The findings of this study revealed that the control group had a significantly higher incidence rate of physiological parameters adverse events. It is observed that $13 \%$ of patients in the study group had mild coma after application of coma arousal technique at 4th week compared with no one in the control group and at the 6th week of the study, it increased to $23 \%$ in the study group compared with only $3 \%$ in the control group. The total mean scores of SMART for the study group increased significantly post application of coma arousal technique compared to the control group throughout the study period. At the 4th and 6th week of the study, it is clear that patients' sedation in study group was significantly in more appropriate level than control group. It was found that mean length of ICU stay and duration of mechanical ventilation was significantly shorter in the study group than in the control group.

Conclusion: application of coma arousal technique had effects on improvement the level of consciousness and sensory and motor modalities associated with a decreased incidence of physiological parameters adverse events.
\end{abstract}

Recommendations: This study recommended that critical care nurses should be incorporated coma arousal technique into a nurse's daily routine in the care of unconscious patients.

Keywords: Coma arousal technique, Clinical outcome, Unconscious.

\section{Introduction}

Consciousness is a state of being with two important aspects, wakefulness and awareness of self and environment ${ }^{(1)}$. Unconsciousness is a condition of being unaware of one's surroundings as in sleep or of being unresponsive to stimulation ${ }^{(2)}$. Meanwhile, it is lack of responses to sensory and motor stimuli as a result of hypoxia; resulting from respiratory insufficiency or shock, metabolic or chemical brain depressants, such as drugs, poisons, ketones, or electrolyte imbalance, a form of pathologic condition such as trauma, seizures, cerebro vascular accident, brain tumors or infection ${ }^{(3)}$. Loss of consciousness can be brief lasting for a few seconds to minutes or sustained, lasting for an hour or longer and often experience decreased quality of life ${ }^{(4)}$. Level of consciousness including three stages; coma, vegetative and minimally conscious. Coma is a pathological state related to severe and prolonged dysfunction of vigilance. Vegetative stage suggests a preservation of autonomic functions (e.g., cardio-vascular, respiratory and thermoregulation functions) and reemergence of the sleep-wake cycle (i.e., periods of spontaneous eyes opening) ${ }^{(5)}$. Behaviorally, there is no response to verbal order and, although moaning may occur, there is no intelligible speech. The minimally conscious stage is characterized by the presence of inconsistent but clearly-discernible behavioral signs of consciousness. Regarding prognosis, the probability of functional recovery at one year following traumatic brain injury is significantly more favorable relative to vegetative stage (50\% vs. $3 \%$ attaining moderate disability). Some patients in minimally conscious stage progress slowly while others remain in this condition permanently (6). 
The outcomes of unconsciousness range from recovery to death and generally last a few days to few weeks, rarely more than 2 to 5 weeks. After this, some patients gradually come out of coma or some may progress to a vegetative state, and some may die. Some patients may remain in a vegetative state for years or even decades. The outcome from coma and vegetative state depends on the cause, location, severity and extent of neurological damage ${ }^{(5)}$. The longer the patient remains in coma more they suffer from a long term cognitive, behavioral and emotional impairment which prevents them from pursuing active and responsible lives after brain injury. Although emergency care, diagnostic technology, medical intervention and nursing care have resulted in increased survival in individuals after brain injury, arousal and cognitive recovery are not guaranted. Arousal is a pre-requisite for all the selective attention necessary for recognizing and processing information. Without arousal, the more complex cognitive process such as sustained attention or concentration necessary for learning cannot occur ${ }^{(7)}$.

Patients with altered level of consciousness experience sensory deprivation because their ability to respond to internal and external stimuli is altered threshold of activation of reticular activating system which may increase in coma patients ${ }^{(8)}$. Therefore, to facilitate the recovery process, coma arousal technique has been developed which is operate on the belief that brain has restorative properties, through environmental or sensory and motor stimulation. So, it can be used as an intervention to overcome of sensory deprivation and may improve brain function and plasticity ${ }^{(1)}$. Application of coma arousal technique for unconscious patients in a systematic manner may improves the brain organization, and functional activity. The rationale is that exposure to sensory and motor stimulation will facilitate both dendrite growth and improve synaptic connectivity for unconscious patients with damaged nervous systems leading to improved cognitive functioning and environmental interaction. Sensory stimulation; is a systematic exposure of a comatose or minimally conscious patient to a variety of environmental stimuli (visual, auditory, tactile, olfactory, and kinesthetic) to improve arousal and recovery. Motor or kinesthetic stimulation considered as a part of structured environment stimulation. It is a pattern of simple physical rehabilitation in intensive care unit performed through passive or active range of motion exercises and bed movement activities ${ }^{(9)}$.

Some patients in coma are awaken slowly and begin to respond normally. Sensory and motor stimulation through coma arousal technique has been suggested as a measure to enhance outcome from coma. Nurse is encouraged to interact with comatose patients through all their sensory system. Nurses who work with coma patients would do well coma arousal technique in their areas to see what they have to offer the comatose patients and their families ${ }^{(10)}$.

\subsection{Significance of the study:}

Unconsciousness has long been recognized as a research priority in critical care, unfortunately, many of the studies in this area suffer from design weaknesses, such as non-standardized practices, so definitive recommendations for clinical practice are difficult to make ${ }^{(3,5)}$. In addition, recent developments in the field of functional neuroimaging have resulted in dramatic evidence that unconscious patients can hear and seemingly retain some cognitive ability ${ }^{(11)}$. Although several studies have been conducted to explore the clinical benefits of coma arousal technique with unconscious patients, none of them was conducted in Egypt, still don't have a clear answer about the clinical outcomes to coma arousal technique for an unconscious patient. Application of sensory and motor stimulation through coma arousal technique for patients with unconscious patient, is found to be feasible, safe with did not increase costs. Moreover; sensory and motor stimulation is arousing the brain by stimulating the reticular activating and increasing the level of cognitive function. It is a significant challenge for nurses as they are responsible for all patients care.

\subsection{Aim of the study}

The aim of the study was to evaluate the effect of coma arousal technique on clinical outcomes of unconscious patients.

\subsection{Research Hypothesis:}

It was hypothesized that the unconscious patients who will subjected to coma arousal technique (study group) will be expected to improve consciousness, will have a significant lower incidence of serious physiological parameters adverse events, with a shorter duration of mechanical ventilation and length of ICU stay compared to (control group) patients who will not subject to coma arousal technique.

\subsection{Research Design}

\section{Subjects and Methods}

The research design used is a quasi-experimental, with a study group subjected to coma arousal technique and a control group not subject it.

\subsection{Setting}

The study was conducted at the neuro, chest and medicine intensive care unit at Ain -Shams University Specialized Hospital. 


\subsection{Sample}

A purposeful sampling of sixty adult patients of both sexes admitted to the previously mentioned ICUs were recruited for this study. The inclusion criteria were patient's aged $\geq 18$ years old with the Rappaport Coma Scale (RCS) score between 9 and 16, on mechanical ventilator for less than 48 hours and hemodynamically stable. Meanwhile, patients with history of impaired hearing; excessive consumption of alcohol and/or narcotic substances; diagnosed injury of the auditory pathways and the cerebral cortex, receiving resuscitative therapies, induced coma by infusion of neuromuscular blockade, quadriplegia and skull fractures in the temporal area or have history of seizure and blindness were excluded from the study. After application of the inclusion and exclusion criteria, the sample of sixty patients were randomly and alternatively divided into two equal groups (study\& control), 30 subjects each. The study group received coma arousal technique while, the control group received the routine hospital nursing care for unconscious patients.

\subsection{Tools}

After reviewing of the related literature, the following tools were used to collect data related to this study:

Tool (I): Demographic and clinical data Sheet: An assessment sheet was developed by the researchers to collect data regarding to patient's age, sex, diagnosis, duration of mechanical ventilation (MV), and ICU length of stay. This tool was filled in once by the researchers.

Tool (II): Physiological parameters adverse events assessment tool: This tool was developed by the researchers to monitor the patients for the occurrence of physiological changes regarding coma arousal technique throughout the study period. The physiological parameters were organized in a flow sheet to document patient's data from the beginning to the end of the study. These parameters were defined as appearance of clinically relevant changes after application of coma arousal technique which including respiratory and heart rates, systolic and diastolic blood pressure, temperature, oxygen saturation, central venous pressure and blood glucose level. These parameters changes including the followings ${ }^{(1,3)}$ :

*Bradypnea: respiratory rate $\leq 12$ cycle/min. $\quad *$ Tachypnea (respiratory rate $\geq 35$ cycle/min).

*Tachycardia: (heart rate $\geq 100 \mathrm{~b} / \mathrm{min}$ ). $\quad *$ Bradycardia: (heart rate $\leq 60 \mathrm{~b} / \mathrm{min}$ ).

*Hypertension: $(\mathrm{SBP} \geq 140 \mathrm{mmHg}, \mathrm{DBP} \geq 90 \mathrm{mmHg}) *$ Hypotension: $(\mathrm{SBP} \leq 95 \mathrm{mmHg}, \mathrm{DBP} \leq 60 \mathrm{mmHg})$.

*Hyperthermia: $\left(\mathrm{T} \geq 37.5{ }^{\circ} \mathrm{C}\right)$. $\quad *$ Desaturation: (oxygen saturation $\leq 90 \%$ ).

*Hypovolemia: (CVP < $3 \mathrm{cmH} 2 \mathrm{O})$. $\quad *$ Hypervolemia: $(\mathrm{CVP}>8 \mathrm{cmH} 2 \mathrm{O})$.

*Hyperglycemia: (Blood Glucose Level (BGL) $\geq 200 \mathrm{mg} / \mathrm{dl}) \quad *$ Hypoglycemia: (BGL < $70 \mathrm{mg} / \mathrm{dl})$.

Tool (III): Rappaport coma scale(RCS): According to American Medical Empire Blue Cross and Blue Shield Association, (2009) ${ }^{(12)}$ explained that RCS is considered the gold standard for clinical/behavioral assessment and the scale is intended to measure accurately the general functional changes over the course of recovery. It was developed to assess patient's level of consciousness regarding conducting coma arousal technique practices. It was adopted from Tolle and Reimer (2003) ${ }^{(13)}$. The scale consists of 32 items that comprise parameters addressing auditory, motor, visual, threat, olfactory, tactile, pain and verbal functions. The maximum score for the four items is 4 . The total score ranges from 0 to 32. The scale classifies the level of consciousness into 5 categories: $0=$ fully consciousness (Level 0), 1-8=Mild coma (Level 1), 9-16=Moderate coma (Level 2), 17-24=Marked coma (Level 3) and 25-32= Extreme/ Deep coma (Level 4).

Tool (IV): Sensory Modality Assessment and Rehabilitation Technique (SMART): According to Baker, (2010) ${ }^{(14)}$ stated that SMART provide a structured and graded assessment of sensory and motor responses of comatose patients in response to stimulation. It was developed to identify signs of consciousness observed regarding "sensory stimulations of coma arousal technique" intended to support cerebral plasticity and improve level of consciousness. It was adopted from Wood, $(1991)^{(15)}$. The sensory assessment has 5 modalities (motor function, tactile, auditory, visual and wakefulness/arousal). The SMART is a hierarchical scale consisting of 5 response levels which is consistent and comparable across the mentioned sensory modalities. The scale classifies the level of responses into 5 categories: absence of response $=($ level 1), reflex response $=($ level 2$)$, withdrawal response $=($ level 3$)$, localization response $=($ level 4$)$ and discrimination response $=($ level 5$)$. The total scores ranged from 5 to 25 , with score 5 indicating severe deficit of sensory function and score 25 representing no deficit.

Tool (V): Motor Activity Assessment Scale (MAAS): This scale is adopted from Devlin et al. (1999) ${ }^{(16)}$ to assess patients' levels of sedation or irritability and restlessness regarding performing coma arousal technique practices. It is a 7-point scale ranging from 0 (unresponsive) to 6 (dangerously agitated). The levels $0-2$ indicate a deeper sedation level affecting the patients' motor activity, wakefulness and consciousness. When patients are calm and cooperative, it indicates level 3, restless and cooperative indicates level 4 and increased motor activity, agitation and uncooperative indicates level 5-6. 


\subsection{Data collection methods}

\subsubsection{Administrative Consideration}

Permission to conduct the study was obtained from the hospital authorities in the neuro, chest and medicine intensive care units at Ain -Shams University Specialized Hospital after explaining the aim and the nature of the study.

\subsubsection{Validity and reliability of tools}

The tools were developed after reviewing of related literature and were tested for its content validity by a jury of six experts in the field (two medical surgical nursing, two critical care nursing educators, one anesthesiologist and one statistician) and ascertain that the tools were relevant, understood, and applicable and modifications were done to ascertain clarity, relevance, applicability, comprehensiveness, and ease for implementation prior to data collection. The reliability and validity of RCS were acceptable in another research done by Barbarito (2007) ${ }^{(17)}$ Cronbach $\alpha 0.87$ and a Kappa coefficient of 0.99 . Also, the reliability and validity of the SMART was assessed by Gill-Thwaites and Munday, (2004) ${ }^{(18)}$ who reported that Cronbach $\alpha 0.89$ and a Kappa coefficient of 0.97 . Concerning MAAS, it was previously tested for validity and reliability and was considered as a valid and reliable sedation scale for use by nurses for mechanically ventilated patients by Devlin et al. (1999) ${ }^{(16)}$.

\subsubsection{Ethical considerations and human rights}

Ethical consideration was done through anonymity of the collected data and confidentiality was maintained. There were no risks that can affect the studied patients during the implementation of this study. All patients were assigned a code number to ensure confidentiality. Written consent was obtained from the patients' family to participate in the study after explaining the purpose of the study and their right to refuse participation or withdrawn from the study at any time. Patients' relatives were also assured that if they did not wish to participate in the study, this would have no effect on the quality of care provided. The care of both patients in the control and intervention groups was, however, unchanged before and after the period of coma arousal technique practices. The ethical demand of doing well, not harming and being fair, thereby appeared to have been met.

\subsubsection{Pilot study}

Pilot study was conducted on $10 \%$ of study sample (6 patients) who met the predetermined selection criteria. It was carried out to test clarity, feasibility and applicability of the different items of the determinant tools and accordingly; some modifications were done and those patients were excluded from the study.

\subsubsection{Procedure of data collection}

The actual fieldwork started at the beginning of June 2015 and was completed by the end of September 2016. It was conducted on four consecutive phases; assessment, planning, implementation and evaluation phases.

- Assessment phase:

The aim of this phase was to assess patient's level of consciousness and identify sensory and motor responses of comatose patients in response to stimulation. Moreover, assess patients' levels of sedation or irritability and restlessness. Initial assessment was carried out by the researcher for all study subjects in both control and study groups to assess the patients who met the inclusive criteria of the study. To collect baseline data, assessment was carried out using demographic and clinical data, physiological adverse events, RCS, SMART and MAAS.

- Planning phase:

Individualized plan of care was developed for the study group based on the findings of the assessment phase and an extensive literature review which was identify all available evidence concerning coma arousal technique with unconscious patients. Priorities, goal, expected outcomes and nursing approaches were formulated into planning of patient care including an improvement scores of: physiological parameters, Rappaport coma, Sensory modality assessment and motor activity. Moreover, duration of mechanical ventilation and the length of ICU stay. In this phase, a colored booklet was developed by the researchers to be distributed to each patient' family in the study group which considered as a reference value for the study group patients and their families.

- Implementation phase:

Both study and control group were followed up twice daily (9-10 Am and 8-9 Pm) for 6 weeks (duration of the study). During this phase, the patient's closest relative of the study group was interviewed to determine the patient's personality characteristics. After 24 hours of patient's admission to the intended ICUs, the researchers reviewed patient's chart to document socio-demographic and health relevant data.

*For the patients in the study group: In this phase the coma arousal technique was implemented by the researchers to all participants involved in the study group as the following: 
- At the first, the researchers documented changes of patient's condition through using physical parameters measurement by monitors respiratory and heart rates, systolic and diastolic blood pressure, temperature, oxygen saturation, central venous pressure and blood glucose level.

- In order to avoid possible sensory overload, the technique was first provided with the routine nursing care with closed monitoring for physiological parameters responses.

-The researchers prepare the patient room through decrease number of visitors, close the door and curtains were drawn to provide privacy, and tried to keep the surroundings as quiet as possible, maintain a good odor in the room before starting coma arousal technique and ensured that the patient is in a resting position (semi-fowler's position or appropriate position to the applied procedure). Then the researchers stood beside the patient's bed (facing the patient to be in the visual field).

- At beginning of session, to ensure optimal benefit and responsiveness, the researchers talking to the patient slowly, in a normal tone of voice and oriented patient to the date, time, and place before implementation the technique.

- Family members involved during application of coma arousal technique with the researchers.

- The researchers provided stimulations for only one modality at a time (no talking while providing stimulation) and presented each stimulus a minimum of 3 times.

- Coma arousal technique included the following stimulations:

A- Kinesthetic stimulation (Motor): This was performed either on bed or on wheelchair, one extremity at a time. Each movement was done 2 times, allowing $1 \mathrm{~min}$ to respond. Movement of arms, the patient's arm was supported at the elbow and hand. Then arm was slowly moved above the head as far as it go. Then it was held for 3 seconds then arm was lowered, keeping the elbow as straight as possible. Movement of legs, the patient's leg was supported at the knee and ankle, and was slowly bent toward the chest as far as possible, held for 3 seconds and then lowered down, attempting to straighten the knee. Movement of head, the head was turned side to side, stretching as far as it could go. Patient's knees were flexed, placing the feet flat on the bed and then laterally rotated keeping the knees together, held for 3 seconds in each position.

B- Tactile stimulation (Sensory): Stimulus was presented for 5 seconds, twice, with 3 seconds' break between each stimulus. It was repeated to right and then, left upper extremities; then right and left lower extremities. Materials used were brush, various cloth textures, sandpapers and cotton ball.

C- Auditory stimulation (Sensory): It was performed through starting conversation with the patient, oriented about his or her name, time, place, date and day. Different stimuli were used in sequence. Each stimulus was presented for 5-10 seconds, twice, with 3 seconds' break, on right side and then on left side. Materials used were ring bell, familiar voices, and religious chants using ear pieces.

D- Visual stimulation (Sensory): It was applied by stimulating the usual attention and tracking eyes to visual stimulus. It was presented for 5 seconds, twice, with 3seconds break between each stimulus in front outer, inner upper and lower quadrant/ field of vision. Materials used were, brightly colored pen light, familiar faces or objects, photographs of family members, and a mirror.

- Rest period was given to the patient 1-2 minutes between each stimulus.

*For the patients in the control group: They received routine hospital care for unconscious patients.

- Evaluation phase:

Evaluation was done for both groups four times; on admission as baseline data, after second week, then fourth week and sixth week later using tools of physiological parameters adverse events assessment, RCS, SMART, and MAAS were considered as primary clinical outcomes. While overall duration of mechanical ventilation and length of ICU stay, were considered as secondary outcomes. Comparison was done between both groups to determine the effect of coma arousal technique on clinical outcomes of unconscious patients.

-At the end of the study and after the evaluation phase, the researchers distributed the colored booklet to each patient' family in the control group which considered as a reference value for the control group patients and their families.

\subsubsection{Statistical analysis:}

The collected data were organized, tabulated and statistically analyzed using the Statistical Package for Social Studies (SPSS) version 21. Following data entry, checking and verification processes were carried out to avoid any errors during data entry. The data were presented in tables and graphs as frequency and percentage.

1. Descriptive statistics: in which quantitative data were presented in the form of mean, standard deviation (SD), range, and qualitative data were presented in the form numbers and percentages.

2. Analytical statistics: used to find out the possible association between two groups. The used tests of significance included:

*Chi-square test $(\chi 2)$ : was used to study association between two qualitative variables.

*Student t-test: is a test of significance used for comparison between two groups having quantitative variables. $\mathrm{P}$ value of $>0.05$ non-significant, $\mathrm{P}$ value of $<0.05$ significant, $\mathrm{P}$ value of $<0.001$ highly significant. 


\section{Results}

Table (1): Demographic and Clinical data characteristics in the study and control group $(n=60)$

\begin{tabular}{|c|c|c|c|c|c|c|}
\hline \multirow{3}{*}{$\begin{array}{c}\text { Demographic and Clinical data } \\
\text { characteristics }\end{array}$} & \multicolumn{4}{|c|}{ Groups } & \multirow{3}{*}{$\mathbf{X}^{2}$} & \multirow{3}{*}{ P-Value } \\
\hline & \multicolumn{2}{|c|}{ Study(n=30) } & \multicolumn{2}{|c|}{ Control(n=30) } & & \\
\hline & No. & $\%$ & No. & $\%$ & & \\
\hline $\begin{array}{l}\text { Age (Years) } \\
\quad \text { Mean } \pm \text { SD }\end{array}$ & \multicolumn{2}{|c|}{$41.5 \pm 10.1$} & \multicolumn{2}{|c|}{$40.3 \pm 11.0$} & $t=0.44$ & 0.66 \\
\hline $\begin{array}{l}\text { Sex } \\
\quad \text { Male } \\
\text { Female }\end{array}$ & $\begin{array}{l}13 \\
17\end{array}$ & $\begin{array}{l}43.0 \\
57.0\end{array}$ & $\begin{array}{l}11 \\
19\end{array}$ & $\begin{array}{l}37.0 \\
63.0\end{array}$ & 0.28 & 0.59 \\
\hline $\begin{array}{l}\text { Diagnosis } \\
\text { Neurological Disorders } \\
\text { Respiratory Disorders } \\
\text { Medical Disorders }\end{array}$ & $\begin{array}{c}15 \\
9 \\
6\end{array}$ & $\begin{array}{l}50.0 \\
30.0 \\
20.0\end{array}$ & $\begin{array}{l}17 \\
8 \\
5\end{array}$ & $\begin{array}{l}57.0 \\
26.0 \\
17.0\end{array}$ & 0.27 & 0.87 \\
\hline
\end{tabular}

Note. t: t-test; $\mathbf{X}^{2}$ : Chi-square test

Table (1) Comparing the two groups (study and control) in relation to demographic and clinical data characteristics, these groups were comparable and no significant differences were noted; in other words, they can be considered homogeneous.

Table (2): Comparison of mean scores regarding physiological parameters changes among study and control groups throughout study period

\begin{tabular}{|c|c|c|c|c|}
\hline \multirow[t]{3}{*}{ physiological parameters } & \multicolumn{2}{|c|}{ Groups } & \multirow[t]{3}{*}{ t-test } & \multirow[t]{3}{*}{ P-Value } \\
\hline & $\operatorname{Study}(n=30)$ & $\operatorname{Control}(n=30)$ & & \\
\hline & Mean \pm SD & Mean \pm SD & & \\
\hline \multicolumn{5}{|l|}{ Respiratory rate } \\
\hline -Baseline $\left(1^{\text {st }}\right.$ day $)$ & $18.3 \pm 1.6$ & $18.2 \pm 1.9$ & 0.22 & 0.82 \\
\hline$-2^{\text {nd }}$ Week & $18.5 \pm 1.7$ & $19.3 \pm 2.1$ & 1.62 & 0.11 \\
\hline$-4^{\text {th }}$ Week & $18.9 \pm 1.8$ & $21.1 \pm 2.0$ & 4.47 & $<0.01 *$ \\
\hline$-6^{\text {th }}$ Week & $19.2 \pm 1.5$ & $23.9 \pm 2.2$ & 9.66 & $<0.001 *$ \\
\hline \multicolumn{5}{|l|}{ Heart rate } \\
\hline -Baseline (1 $1^{\text {st }}$ day $)$ & $81.5 \pm 9.1$ & $81.7 \pm 8.7$ & 0.08 & 0.93 \\
\hline$-2^{\text {nd }}$ Week & $85.4 \pm 8.6$ & $89.2 \pm 6.3$ & 1.95 & 0.05 \\
\hline$-4^{\text {th }}$ Week & $88.6 \pm 8.3$ & $94.1 \pm 5.2$ & 3.07 & $<0.01 *$ \\
\hline$-6^{\text {th }}$ Week & $88.8 \pm 4.2$ & $110.9 \pm 6.3$ & 15.9 & $<0.001 *$ \\
\hline \multicolumn{5}{|l|}{ Systolic blood pressure } \\
\hline -Baseline ( $1^{\text {st }}$ day $)$ & $115.6 \pm 5.9$ & $117.2 \pm 3.1$ & 1.32 & 0.19 \\
\hline$-2^{\text {nd }}$ Week & $117.3 \pm 4.1$ & $125.1 \pm 9.6$ & 4.09 & $0.01 *$ \\
\hline$-4^{\text {th }}$ Week & $117.9 \pm 5.0$ & $132.5 \pm 0.5$ & 15.9 & $<0.001 *$ \\
\hline$-6^{\text {th }}$ Week & $118.0 \pm 3.2$ & $138.6 \pm 2.4$ & 28.2 & $<0.0001 *$ \\
\hline \multicolumn{5}{|l|}{ Diastolic blood pressure } \\
\hline -Baseline ( $1^{\text {st }}$ day $)$ & $85.0 \pm 2.1$ & $84.9 \pm 1.9$ & 0.19 & 0.85 \\
\hline$-2^{\text {nd }}$ Week & $85.1 \pm 2.3$ & $87.2 \pm 2.6$ & 3.31 & $0.01 *$ \\
\hline$-4^{\text {th }}$ Week & $85.3 \pm 2.9$ & $95.1 \pm 3.1$ & 12.64 & $<0.001 *$ \\
\hline$-6^{\text {th }}$ Week & $85.0 \pm 2.8$ & $97.9 \pm 1.4$ & 22.57 & $<0.0001 *$ \\
\hline \multicolumn{5}{|l|}{ Temperature } \\
\hline -Baseline $\left(1^{\text {st }}\right.$ day $)$ & $36.8 \pm 0.9$ & $36.7 \pm 0.7$ & 0.48 & 0.63 \\
\hline$-2^{\text {nd }}$ Week & $36.9 \pm 0.8$ & $36.9 \pm 1.2$ & $\mathbf{0 . 0}$ & 1.0 \\
\hline$-4^{\text {th }}$ Week & $37.1 \pm 0.2$ & $37.2 \pm 1.1$ & 0.49 & 0.62 \\
\hline$-6^{\text {th }}$ Week & $37.0 \pm 0.1$ & $37.3 \pm 1.5$ & 1.09 & 0.27 \\
\hline \multicolumn{5}{|l|}{ Oxygen saturation } \\
\hline -Baseline ( $1^{\text {st }}$ day $)$ & $97.3 \pm 1.9$ & $97.2 \pm 1.7$ & 0.21 & 0.83 \\
\hline$-2^{\text {nd }}$ Week & $97.7 \pm 2.1$ & $97.0 \pm 0.6$ & 1.75 & 0.08 \\
\hline$-4^{\text {th }}$ Week & $97.9 \pm 1.2$ & $96.4 \pm 1.1$ & 5.04 & $<0.01 *$ \\
\hline$-6^{\text {th }}$ Week & $98.6 \pm 2.3$ & $94.1 \pm 2.1$ & 7.91 & $<0.001 *$ \\
\hline \multicolumn{5}{|l|}{ Central venous pressure } \\
\hline -Baseline ( $1^{\text {st }}$ day $)$ & $9.2 \pm 1.9$ & $9.4 \pm 1.8$ & 0.42 & 0.67 \\
\hline$-2^{\text {nd }}$ Week & $9.0 \pm 1.3$ & $9.7 \pm 2.1$ & 1.55 & 0.12 \\
\hline$-4^{\text {th }}$ Week & $9.6 \pm 2.1$ & $9.9 \pm 2.6$ & 0.49 & 0.62 \\
\hline$-6^{\text {th }}$ Week & $9.8 \pm 2.2$ & $10.1 \pm 2.1$ & 0.54 & 0.59 \\
\hline \multicolumn{5}{|l|}{ Blood glucose level } \\
\hline -Baseline ( $1^{\text {st }}$ day $)$ & $124 \pm 6.5$ & $126 \pm 4.6$ & 1.38 & 0.17 \\
\hline$-2^{\text {nd }}$ Week & $122 \pm 9.3$ & $131 \pm 1.2$ & 5.26 & $<0.01 *$ \\
\hline$-4^{\text {th }}$ Week & $122 \pm 9.4$ & $143 \pm 2.9$ & 11.69 & $<0.001 *$ \\
\hline$-6^{\text {th }}$ Week & $120 \pm 8.9$ & $165 \pm 4.3$ & 24.94 & $<0.0001 *$ \\
\hline
\end{tabular}

(*) statistically significant $<0.05$

Table (2) reveals that there were no statistically significant differences regarding to mean score values of respiratory and heart rates at the $1^{\text {st }}$ day and $2^{\text {nd }}$ week for the study and control groups, it can be noted that the mean values of respiratory and heart rates for the study group remained relatively constant with normal value 
throughout the study period after implementation of coma arousal technique. Meanwhile, the mean values for the control group were fluctuating throughout the study period and heading to increase above normal value, the differences between the two groups were highly significant at $4^{\text {th }}$ and $6^{\text {th }}$ week $(\mathrm{P}<0.01$ and $<0.001$, respectively). The values of oxygen saturation in control group were declined throughout the study period, meanwhile, it increased for the study group with statistically significant differences between both groups only at $4^{\text {th }}$ and $6^{\text {th }}$ week $(\mathrm{P}<0.01$ and $<0.001$, respectively). The mean systolic blood pressure values for the study group also remained relatively constant throughout the study period, it was $115.6 \pm 5.9$ at the $1^{\text {st }}$ day and $118.0 \pm 3.2$ at the $6^{\text {th }}$ week of the study. While the mean values for the control group increased from $117.2 \pm 3.1$ at the $1^{\text {st }}$ day of the study to $138.6 \pm 2.4 \mathrm{mmHg}$ at the $6^{\text {th }}$ week. Also, diastolic blood pressure did not dramatically change from beginning to the end of the study for the study group. But it was significantly increased among patients in the control group with statistically significant differences regarding systolic and diastolic blood pressure between both groups at $2^{\text {nd }}, 4^{\text {th }}$ and $6^{\text {th }}$ week of the study. The table also discovers that the mean averages of blood glucose level within study group decreased from $124 \pm 6.5$ at the $1^{\text {st }}$ day of the study to $120 \pm 8.9$ at the $6^{\text {th }}$ week. While the mean values for the control group was $126 \pm 4.6$ at the $1^{\text {st }}$ day which was increased to $165 \pm 4.3$ at the $6^{\text {th }}$ week of the study with statistically significant differences between both groups at $2^{\text {nd }}, 4^{\text {th }}$ and $6^{\text {th }}$ week $(\mathrm{P}<0.01,<0.001$ and $<0.0001$, respectively). Meanwhile, there were no statistically significant differences between both groups regarding the mean values of temperature and central venous pressure throughout the study period.

Table (3): Comparison of incidence of serious physiological parameters adverse events among study and control groups at the $6^{\text {th }}$ Week of the study (primary clinical outcome)

\begin{tabular}{|c|c|c|c|c|c|c|}
\hline \multirow[t]{3}{*}{ physiological adverse events } & \multicolumn{4}{|c|}{ Groups } & \multirow[t]{3}{*}{$\mathbf{X}^{2}$} & \multirow[t]{3}{*}{ P-Value } \\
\hline & \multirow{2}{*}{\multicolumn{2}{|c|}{ Study(n=30) }} & \multicolumn{2}{|c|}{ Control(n=30) } & & \\
\hline & & $\%$ & No. & $\%$ & & \\
\hline \multicolumn{7}{|l|}{ Cardiovascular adverse events } \\
\hline -Tachycardia & 4 & 13.0 & 22 & 73.0 & 21.9 & $<0.001 *$ \\
\hline -Bradycardia & 1 & 3.0 & 3 & 10.0 & 1.07 & 0.30 \\
\hline -Hypertension & 2 & 7.0 & 25 & 83.0 & 35.6 & $<0.001 *$ \\
\hline -Hypotension & 1 & 3.0 & 1 & 3.0 & 0.0 & 1.0 \\
\hline -Hypervolemia & 4 & 13.0 & 16 & 53.0 & 10.80 & $0.001 *$ \\
\hline -Hypovolemia & 1 & 3.0 & $\mathbf{0}$ & 0.0 & 1.01 & 0.31 \\
\hline \multicolumn{7}{|l|}{ Respiratory adverse events } \\
\hline -Tachypnea & 5 & 17.0 & 24 & 80.0 & 24.1 & $<0.001 *$ \\
\hline -Bradypnea & 1 & 3.0 & 3 & 10.0 & 1.07 & 0.30 \\
\hline -Desaturation & 1 & 3.0 & 15 & 50.0 & 16.7 & $<0.001 *$ \\
\hline \multicolumn{7}{|l|}{ Metabolic adverse events } \\
\hline -Hyperthermia & 2 & 7.0 & 5 & 17.0 & 1.45 & 0.22 \\
\hline -Hyperglycemia & 3 & 10.0 & 14 & 47.0 & 9.93 & $0.001 *$ \\
\hline
\end{tabular}

(*) statistically significant $<0.05$

Table (3) presents the physiological parameters adverse events among the study and control groups as a primary clinical outcome. Regarding cardiovascular adverse events, there was a highly significant difference between the two groups $(\mathrm{p}<0.001)$ as regards occurrence of tachycardia $(13 \%$ for the study vs. $73 \%$ for the control group), hypertension (7\% for the study vs. $83 \%$ for the control group) and hypervolemia (13\% for the study vs. $53 \%$ for the control group, $\mathrm{P}=0.001$ ). Regarding respiratory adverse events, there was a highly significant difference between the two groups $(\mathrm{p}<0.001)$ as regards occurrence of tachypnea $(17 \%$ for the study vs. $80 \%$ for the control group) and desaturation (3\% for the study vs. $50 \%$ for the control group). The table also reveals that regarding metabolic adverse events, there was a highly significant difference between the two groups $(\mathrm{p}=0.001)$ as regards occurrence of hyperglycemia ( $10 \%$ for the study vs. $47 \%$ for the control group).

Table (4): Comparison the changes in the level of consciousness (RCS) among study and control groups throughout study period (primary clinical outcome)

\begin{tabular}{|c|c|c|c|c|c|c|}
\hline \multirow{3}{*}{$\begin{array}{l}\text { level of consciousness } \\
\text { (RCS) }\end{array}$} & \multicolumn{4}{|c|}{ Groups } & \multirow[t]{3}{*}{$\mathbf{X}^{2}$} & \multirow[t]{3}{*}{ P-Value } \\
\hline & \multicolumn{2}{|c|}{ Study $(n=30)$} & \multicolumn{2}{|c|}{ Control(n=30) } & & \\
\hline & No. & $\%$ & No. & $\%$ & & \\
\hline Baseline $\left(1^{\text {st }}\right.$ Day $)$ & & & & & & \\
\hline -Fully consciousness (Level 0) & 0 & 0.0 & 0 & 0.0 & & \\
\hline -Mild coma $(1-8$, Level 1) & $\mathbf{0}$ & $\mathbf{0 . 0}$ & $\mathbf{0}$ & $\mathbf{0 . 0}$ & -- & -- \\
\hline -Moderate coma (9-16, Level 2) & 30 & 100.0 & 30 & 100.0 & & \\
\hline -Marked coma $(17-24$, Level 3) & $\mathbf{0}$ & $\mathbf{0 . 0}$ & $\mathbf{0}$ & $\mathbf{0 . 0}$ & & \\
\hline -Deep coma $(25-32$, Level 4) & $\mathbf{0}$ & 0.0 & $\mathbf{0}$ & 0.0 & & \\
\hline$\underline{2}^{\text {nd }}$ Week & & & & & & \\
\hline$\overline{\text {-Fully consciousness (Level 0) }}$ & $\mathbf{0}$ & 0.0 & $\mathbf{0}$ & 0.0 & & \\
\hline -Mild coma $(1-8$, Level 1$)$ & 3 & 10.0 & $\mathbf{0}$ & $\mathbf{0 . 0}$ & 4.07 & 0.25 \\
\hline -Moderate coma (9-16, Level 2) & 26 & 87.0 & 28 & 94.0 & & \\
\hline
\end{tabular}




\begin{tabular}{|c|c|c|c|c|c|c|}
\hline $\begin{array}{l}\text {-Marked coma }(17-24, \text { Level } 3) \\
\text {-Deep coma }(25-32, \text { Level } 4)\end{array}$ & $\begin{array}{l}\mathbf{1} \\
\mathbf{0}\end{array}$ & $\begin{array}{l}3.0 \\
0.0\end{array}$ & 1 & $\begin{array}{l}3.0 \\
3.0\end{array}$ & & \\
\hline $4^{\text {th }}$ Week & & & & & \multirow{6}{*}{8.37} & \multirow{6}{*}{$0.03 *$} \\
\hline$\overline{\text {-Fully consciousness (Level } 0)}$ & $\mathbf{0}$ & 0.0 & $\mathbf{0}$ & 0.0 & & \\
\hline -Mild coma $(1-8$, Level 1$)$ & 4 & 13.0 & $\mathbf{0}$ & 0.0 & & \\
\hline -Moderate coma (9-16, Level 2$)$ & 24 & 80.0 & 22 & 73.0 & & \\
\hline -Marked coma (17-24, Level 3) & 2 & 7.0 & 5 & 17.0 & & \\
\hline -Deep coma (25-32, Level 4) & $\mathbf{0}$ & 0.0 & 3 & 10.0 & & \\
\hline $6^{\text {th }}$ Week & & & & & \multirow{6}{*}{12.89} & \multirow{6}{*}{$0.01 *$} \\
\hline -Fully consciousness (Level 0) & 3 & 10.0 & $\mathbf{0}$ & 0.0 & & \\
\hline -Mild coma $(1-8$, Level 1$)$ & 7 & 23.0 & 1 & 3.0 & & \\
\hline -Moderate coma (9-16, Level 2$)$ & 18 & 60.0 & 20 & 67.0 & & \\
\hline -Marked coma $(17-24$, Level 3) & 2 & 7.0 & 5 & 17.0 & & \\
\hline -Deep coma (25-32, Level 4) & $\mathbf{0}$ & 0.0 & 4 & 13.0 & & \\
\hline
\end{tabular}

(*) statistically significant $<0.05$

(--) no valid statistical test

Table (4) illustrates that there were statistically significant differences among study and control groups regarding the changes in the level of consciousness (RCS) as a primary clinical outcome at the $4^{\text {th }}$ and $6^{\text {th }}$ week of the study ( $\mathrm{P}=0.03$ and 0.01 , respectively). It is observed that $13 \%$ of patients in the study group had mild coma after application of coma arousal technique at $4^{\text {th }}$ week compared with no one in the control group and at the $6^{\text {th }}$ week of the study, it increased to $23 \%$ in the study group compared with only $3 \%$ in the control group.

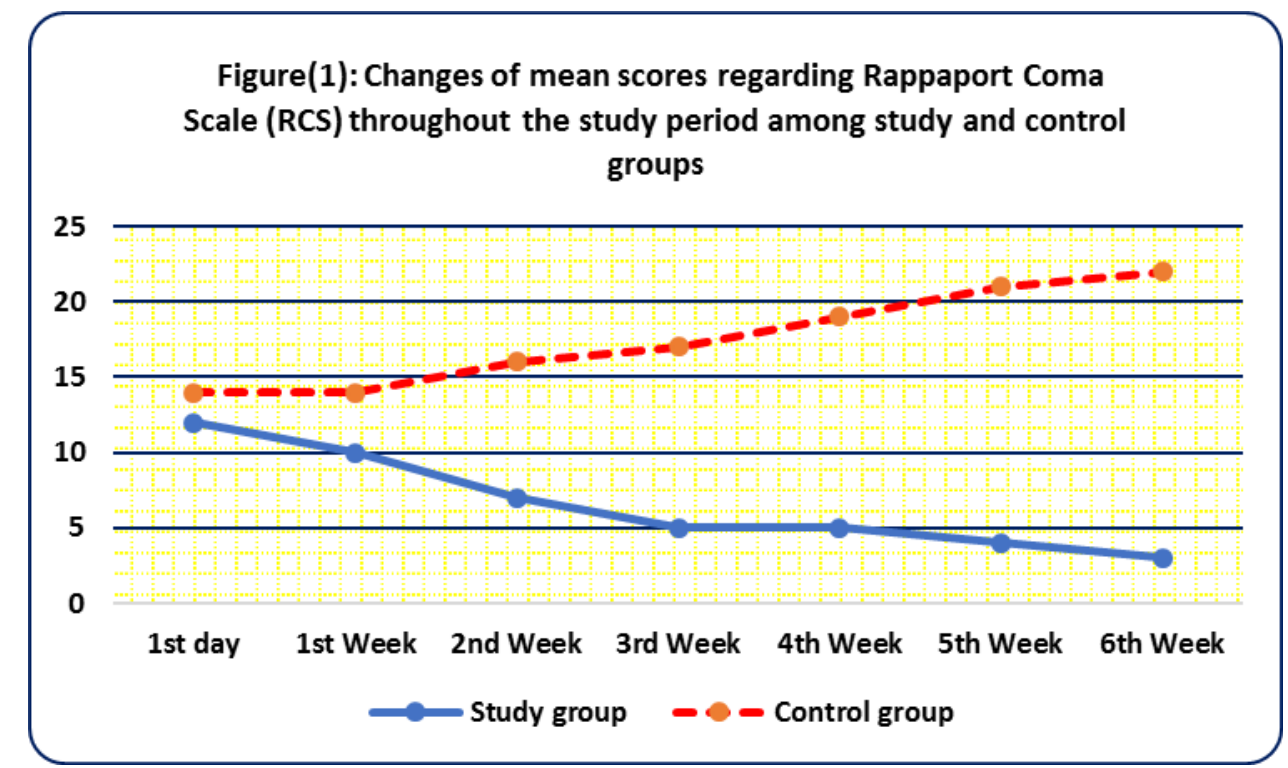

Figure (1) demonstrates that the two groups were similar at baseline, patients in the study group had a lower mean score all over the study period after application of coma arousal technique which reflecting improvement in conscious level regarding rappaport coma scale than patients in the control group who had a higher mean score all over the study period.

Table (5): Comparison of mean scores regarding Sensory Modality Assessment and Rehabilitation Technique (SMART) among study and control groups throughout study period (primary clinical outcome)

\begin{tabular}{|c|c|c|c|c|}
\hline \multirow{3}{*}{$\begin{array}{c}\text { SMART } \\
\text { Modalities }\end{array}$} & \multicolumn{2}{|c|}{ Groups } & \multirow{3}{*}{ t-test } & \multirow{3}{*}{ P-Value } \\
\hline & $\operatorname{Study}(n=30)$ & Control(n=30) & & \\
\hline & Mean \pm SD & Mean \pm SD & & \\
\hline \multicolumn{5}{|l|}{ Motor function } \\
\hline -Baseline $\left(1^{\text {st }}\right.$ day $)$ & $2.0 \pm 0.0$ & $2.0 \pm 0.0$ & -- & -- \\
\hline$-2^{\text {nd }}$ Week & $2.3 \pm 0.5$ & $2.1 \pm 0.1$ & 2.15 & $0.03 *$ \\
\hline$-4^{\text {th }}$ Week & $2.9 \pm 0.7$ & $2.1 \pm 0.1$ & 6.19 & $<0.01 *$ \\
\hline$-6^{\text {th }}$ Week & $3.1 \pm 0.9$ & $2.2 \pm 0.3$ & 5.20 & $<0.001 *$ \\
\hline \multicolumn{5}{|l|}{ Tactile } \\
\hline -Baseline $\left(1^{\text {st }}\right.$ day $)$ & $2.0 \pm 0.0$ & $2.0 \pm 0.0$ & -- & -- \\
\hline$-2^{\text {nd }}$ Week & $2.2 \pm 1.0$ & $2.0 \pm 0.0$ & 1.09 & 0.28 \\
\hline$-4^{\text {th }}$ Week & $2.8 \pm 0.9$ & $2.3 \pm 0.2$ & 2.97 & $0.04 *$ \\
\hline$-6^{\text {th }}$ Week & $3.1 \pm 1.1$ & $2.4 \pm 0.4$ & 3.27 & $0.01 *$ \\
\hline \multicolumn{5}{|l|}{ Auditory } \\
\hline -Baseline $\left(1^{\text {st }}\right.$ day $)$ & $2.0 \pm 0.0$ & $2.0 \pm 0.0$ & -- & -- \\
\hline$-2^{\text {nd }}$ Week & $2.6 \pm 0.6$ & $2.1 \pm 0.2$ & 4.33 & $<0.01 *$ \\
\hline$-4^{\text {th }}$ Week & $3.1 \pm 0.8$ & $2.3 \pm 0.2$ & 5.31 & $<0.001 *$ \\
\hline
\end{tabular}




\begin{tabular}{|c|c|c|c|c|}
\hline$-6^{\text {th }}$ Week & $3.4 \pm 1.0$ & $2.3 \pm 0.2$ & 5.91 & $<0.001 *$ \\
\hline $\begin{array}{l}\text { Visual } \\
\left.\text {-Baseline ( } 1^{\text {st }} \text { day }\right) \\
-2^{\text {nd }} \text { Week } \\
-4^{\text {th }} \text { Week } \\
-6^{\text {th }} \text { Week }\end{array}$ & $\begin{array}{l}2.0 \pm 0.0 \\
2.1 \pm 0.2 \\
2.4 \pm 0.3 \\
2.9 \pm 0.7\end{array}$ & $\begin{array}{l}2.0 \pm 0.0 \\
2.1 \pm 0.1 \\
2.1 \pm 0.1 \\
2.2 \pm 0.2\end{array}$ & $\begin{array}{c}-- \\
0.0 \\
5.19 \\
5.27\end{array}$ & $\begin{array}{c}-- \\
1.0 \\
<0.01 * \\
<0.001 *\end{array}$ \\
\hline $\begin{array}{l}\text { Wakefulness/arousal } \\
- \text { Baseline }\left(1^{\text {st }} \text { day }\right) \\
-2^{\text {nd }} \text { Week } \\
-4^{\text {th }} \text { Week } \\
-6^{\text {th }} \text { Week }\end{array}$ & $\begin{array}{l}2.0 \pm 0.0 \\
2.2 \pm 0.2 \\
2.8 \pm 0.3 \\
3.4 \pm 0.5\end{array}$ & $\begin{array}{l}2.0 \pm 0.0 \\
2.1 \pm 0.3 \\
2.3 \pm 0.3 \\
2.3 \pm 0.5\end{array}$ & $\begin{array}{l}-- \\
1.52 \\
6.45 \\
8.52\end{array}$ & $\begin{array}{c}-- \\
0.13 \\
<0.01 * \\
<0.001 *\end{array}$ \\
\hline
\end{tabular}

(*) statistically significant $<0.05$

Table (5) shows that at the 1st day before application of coma arousal technique, it was noticed that all mean scores of motor function, tactile, auditory, visual and wakefulness/arousal responses, were equal for both groups $(2.0 \pm 0.0)$. Meanwhile, on $2^{\text {nd }}, 4^{\text {th }}$ and $6^{\text {th }}$ weeks, the motor function mean scores were increased significantly in the study group to $(2.3 \pm 0.5,2.9 \pm 0.7$ and $3.1 \pm 0.9)$, compared to control group $(2.1 \pm 0.1,2.1 \pm 0.1$ and 2.2 \pm 0.3 ), respectively. Moreover, tactile mean scores for the study group after application of the technique was increased to $(2.2 \pm 1.0,2.8 \pm 0.9$ and 3.1 \pm 1.1$)$ compared to $(2.0 \pm 0.0,2.3 \pm 0.2$ and $2.4 \pm 0.4)$ of the control group on $2^{\text {nd }}, 4^{\text {th }}$ and $6^{\text {th }}$ week, respectively, with statistically significant differences between both groups on $4^{\text {th }}$ and $6^{\text {th }}$ week of the study. Additionally, the mean scores of auditory responses of study group were $(2.6 \pm 0.6,3.1 \pm 0.8$ and 3.4 \pm 1.0 ) on 2 nd, 4th and 6th weeks respectively while the mean score of the control group was increased gradually on the $2^{\text {nd }}$ week $(2.1 \pm 0.2)$ and then became almost equal on the $4^{\text {th }}$ and $6^{\text {th }}$ week $(2.3 \pm 0.2)$ with statistically significant differences between both groups on $2^{\text {nd }}, 4^{\text {th }}$, and $6^{\text {th }}$ week of the study $(\mathrm{P}<0.01,<0.001$ and $<0.001$, respectively). The visual mean scores of the study group was increased to $(2.1 \pm 0.2,2.4 \pm 0.3$ and $2.9 \pm 0.7)$ compared to $(2.1 \pm 0.1,2.1 \pm 0.1$ and $2.2 \pm 0.2)$ for the control group on $2^{\text {nd }}, 4^{\text {th }}$, and $6^{\text {th }}$ week, respectively. Moreover, mean scores of wakefulness/arousal for the study group was increased to $(2.2 \pm 0.2,2.8 \pm 0.3$ and $3.4 \pm 0.5)$ compared to $(2.1 \pm 0.3,2.3 \pm 0.3$ and $2.3 \pm 0.5))$ of the control group on $2 \mathrm{nd}$, 4th, and 6th week, respectively.

\section{Figure(2): Total mean scores of SMART among study and control} groups througnout study period of coma arousal tecnnique application

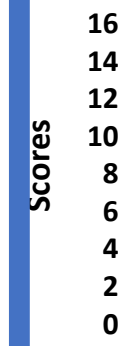

Study group

Control group

1st day 2nd Week 4th Week 6th Week

Study period

Figure (2) demonstrates that the total mean scores of SMART was $(10.0 \pm 00,11.4 \pm 2.5,14.0 \pm 3.0$ and $15.9 \pm 4.2)$ of the study group which increased significantly post application of coma arousal technique compared to the control group $(10.00 \pm 00,10.4 \pm 0.7,11.1 \pm 0.9$ and $11.4 \pm 1.6)$ at 1 st day, 2nd, 4th, and 6th week, respectively.

Table (6): Comparison of total mean scores regarding Motor Activity Assessment Scale (MAAS) among study and control groups throughout study period (primary clinical outcome)

\begin{tabular}{|c|c|c|c|c|}
\hline \multirow[t]{3}{*}{ MAAS } & \multicolumn{2}{|c|}{ Groups } & \multirow{3}{*}{ t-test } & \multirow{3}{*}{ P-Value } \\
\hline & $\operatorname{Study}(n=30)$ & $\operatorname{Control}(n=30)$ & & \\
\hline & Mean \pm SD & Mean \pm SD & & \\
\hline Baseline $\left(1^{\text {st }}\right.$ Day $)$ & $1.4 \pm 0.6$ & $1.5 \pm 0.3$ & 0.82 & 0.42 \\
\hline $2^{\text {nd }}$ Week & $1.7 \pm 0.3$ & $1.6 \pm 0.5$ & 0.93 & 0.35 \\
\hline $4^{\text {th }}$ Week & $2.1 \pm 0.9$ & $1.6 \pm 0.4$ & 2.78 & $0.01 *$ \\
\hline $6^{\text {th }}$ Week & $2.6 \pm 1.3$ & $1.8 \pm 0.3$ & 3.28 & 0.001* \\
\hline
\end{tabular}

(*) statistically significant $<0.05$ 
Table (6) shows the total mean scores regarding MAAS among study and control groups as a primary clinical outcome. There was no statistical significant difference between the study and control groups at the first day of the study $(1.4 \pm 0.6$ vs $1.5 \pm 0.3$, respectively, $\mathrm{P}=0.42)$ and on the $2^{\text {nd }}$ week $(1.7 \pm 0.3$ vs $1.6 \pm 0.5$, respectively, $\mathrm{P}=0.35)$. Meanwhile, the mean scores of MAAS were compared between the two groups at the $4^{\text {th }}$ and $6^{\text {th }}$ week of the study, it is clear that patients' sedation in study group was significantly in more appropriate level than control group ( $\mathrm{P}=0.01$ and 0.001 , respectively).

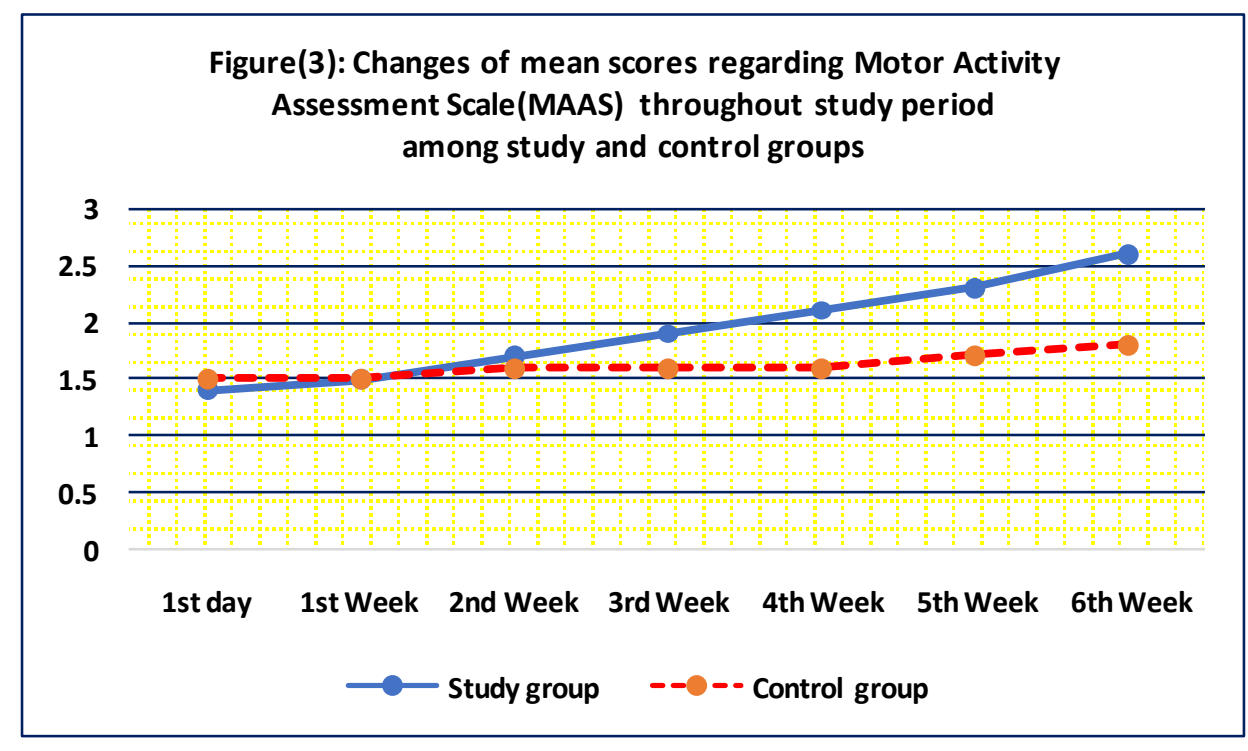

Figure (3) demonstrates the changes in the mean scores of MAAS throughout the study period in the study and control groups. Compared with control group, patients in the study group seemed to be more alert and calm according to the MAAS throughout the study period. The results also show that patients in the study group who received coma arousal technique tended to "stay" in MAAS level 2-3 (calm, cooperative and responsive to touch). It can be observed from the same figure that patients in the control group seemed to be more restlessness with deeper sedation level according to MAAS throughout the study period.

Table (7): Comparison of mean scores regarding duration of mechanical ventilation and length of ICU stay among study and control groups at the $6^{\text {th }}$ Week of the study (secondary outcomes)

\begin{tabular}{|c|c|c|c|c|}
\hline \multirow[t]{3}{*}{ Secondary outcomes } & \multicolumn{2}{|c|}{ Groups } & \multirow[t]{3}{*}{ t-test } & \multirow[t]{3}{*}{ P-Value } \\
\hline & $\operatorname{Study}(n=30)$ & Control(n=30) & & \\
\hline & Mean \pm SD & Mean \pm SD & & \\
\hline Length of ICU stay (Day). & $9.1 \pm 0.4$ & $15.1 \pm 1.2$ & 25.98 & $<0.001 *$ \\
\hline Duration of mechanical ventilation & $5.7 \pm 1.6$ & $10.3 \pm 0.8$ & 14.08 & $<0.001 *$ \\
\hline
\end{tabular}

(*) statistically significant $<0.05$

Table (7) reveals that the mean length of ICU stay for the study group was $9.1 \pm 0.4$ day compared to $15.1 \pm 1.2$ day for the control group with highly significant differences between the two groups $(\mathrm{P}<0.001)$. Also, it was found that the mean duration of mechanical ventilation was significantly shorter in the study group than in the control group (5.7 \pm 1.6 days vs.10.3 \pm 0.8 days respectively, $\mathrm{P}<0.001)$.

\section{Discussion}

Caring for critically ill patients in ICUs is challenging for critical care nursing. An unconscious patient is a fully depends on nurses for his/ her recovery, thus it is the nurse's responsibility to think critically always before intervening (McNett, 2007) ${ }^{(19)}$. Coma arousal technique aims to provide multiple sensory and motor stimulation to patients in coma or vegetative state. It is hoped that with intense and repetitive stimulation, the patient will awaken and return to a higher level of functioning. Coma arousal therapy is believed to provide the sensory stimulation needed to activate the reticular system, which is responsible for maintaining consciousness (Corner et al., 2012) ${ }^{(20)}$. So, the critical care nurse play a more active and meaningful role through application of coma arousal technique into the conventional care for patients with altered level of consciousness to enhance recovery (Christakou et al.,2013) ${ }^{(21)}$. 
The aim of this study was to evaluate the effect of coma arousal technique on clinical outcomes of unconscious patients. It was hypothesized that the unconscious patients who will subjected to coma arousal technique (study group) will be expected to improve consciousness, will have a significant lower incidence of serious physiological parameters adverse events, with a shorter duration of mechanical ventilation and length of ICU stay compared to (control group) patients who will not subject to coma arousal technique.The results have shown that the study and control groups were homogeneous in respect to their age, sex, and all clinical data characteristics. This similarity in both groups was necessary to obviate any undesirable confounding effect of these variables on the outcomes of the study. The present study illustrated that the mean age among study and control subjects was $(41.5 \pm 10.1$ vs $40.3 \pm 11.0$, respectively), and more than half of the studied sample was female with neurological disorders. This finding was congruent with Zhang,(2003) ${ }^{(11)}$, who reported that the majority of age among studied groups was ranged from 40 to 50 years. In the same line, (Petrie and Sabin,2005) (22) mentioned that more than half of study subjects with head injury were females and in the age group of 40 years or more years old and are most likely to sustain a traumatic brain injury.

Concerning primary clinical outcome regarding physiological parameters changes among study and control groups, the findings of the present study found that no physiological adverse effects of coma arousal technique application on patient's clinical condition in study group compared with patients in the control group. Nearly all physiological parameters (respiratory and heart rates, systolic and diastolic blood pressure, oxygen saturation and blood glucose level) reflected both significantly improvement and stability on the patients of the study group, compared with those patients of the control group. Stability of these physiological parameters within the normal values may be attributed to the balancing effects of coma arousal technique on both sympathetic and parasympathetic nervous system. These findings are consistent with results of Amir et al., $(2015)^{(23)}$ reported that unconscious patients who were exposed to early and repeated sensory and motor stimulation demonstrated a positive recovery of brain function without compromising cerebral dynamic or cardiopulmonary functions. Similarly, Hassan et al., (2010) ${ }^{(24)}$ discovered that there were no negative effects associated with exposure to coma arousal technique, with no significant changes being observed in, BP, pulse, $\mathrm{RR}$, mean arterial pressure, $\mathrm{SaO} 2$ level, or level of restlessness for any of the study participants. In the same line, Mohamed (2004) ${ }^{(25)}$ found that sensory stimulation leads to a decrease in cardiac rhythm and blood pressure that lasted 2-3 hours after termination of the stimulus. In addition, Kalani et al., (2016) ${ }^{(26)}$ found that the statistically significant alterations were in the values of oxygen saturation, blood glucose level and breathing frequency.

Regarding to the incidence of serious physiological parameters adverse events among study and control groups at the end of the study, the present study revealed that the control group had a significantly higher incidence rate of physiological parameters adverse events, such occurrence of tachycardia, hypertension, hypervolemia, tachypnea, desaturation and hyperglycemia than patients in the study group. There are evidences in the literature that unconscious patients have neurological and physiological positive responses with sensory and motor stimulation ${ }^{(22,4,6,12,15)}$. On the contrary, Megha et al., (2013) ${ }^{(27)}$ reported that there was clearly correlation between coma arousal technique application and increases in BP, HR, RR, ICP, body movement and facial movement.

The major finding of this study was that the application of coma arousal technique on patients of the study group improved their conscious level when compared with routine hospital care for unconscious patients in the control group. The study revealed that slightly more than one tenth of patients in the study group had mild coma compared with no one in the study group, at the $4^{\text {th }}$ week of the study and at the 6 th week (the end of the study), it increased to slightly less than quarter in the study group compared with only less than one tenth in the control group. This improvement can be explained through understanding coma arousal theories that emphasized on human brain grows and adapts through utilization and increasing environmental stimulation, this theory was the base in developing the current coma arousal technique(El-said,2011) ${ }^{(28)}$. Evidence from studies has illustrated that sensory deprivation leads to physical deterioration of the brain and sensory stimulation increases the level of arousal and awareness through stimulating the reticular activating system (Moattari et al.,2016) ${ }^{(29)}$. Developments in neuroscience provide additional support for implementing sensory stimulation in unconscious patients to promote "rewiring" of neuronal networks. The brain has spare capacity and ability to reorganize its functions, whenever there is damage to one part of brain the spare or non-active areas assume the functions of damaged area by a process of reorganization (McNett, 2007) ${ }^{(19)}$. The brain also has capacity to duplicate neuronal pathway in case existing pathway is damaged (Mandeep et al.,2013) ${ }^{(30)}$. These explanations are in agreement with Hashmi (2012) ${ }^{(31)}$ who reported that application of appropriate arousal practices improves recovery of consciousness. Goudarzi et al., (2010) ${ }^{(32)}$ examined the impact of a sensory stimulation to consciousness level in coma patients. Their findings showed that duration to reach $\mathrm{RCS}=1-8$ was significantly shorter in the experimental group than the control group. Moreover, Simões et al., (2012) ${ }^{(33)}$ examined the effect of organized voice auditory stimulation, which was performed by a nurse, on the length of coma. The results indicated that the intervention group has become conscious from the 5th day and control group from the 
10th day. In the same line, Happ et al., (2011) ${ }^{(34)}$ investigated the effect of coma arousal technique inputs in addition to regular family meeting on comatose patients. They found that consciousness level in the intervention group was significantly higher than the control group.

The present study finding showed that the mean scores of Rappaport coma scale (RCS) decreased significantly in study group than control group after application of coma arousal technique throughout study period which reflecting improvement in conscious level based on RCS that arouse the brain by improving neuronal organization, increased numbers of dendrite spines, thus stimulating the reticular activating system and increasing the level of sensory function (Bickmore et al.,2010) ${ }^{(35)}$. Meanwhile, patients in the control group had a higher mean score, reflecting more deterioration in conscious level based on RCS throughout study period. This result was in line with Amir et al., (2015) ${ }^{(23)}$ who concluded that the mean scores of RCS after application of stimulation program was significantly improved for study group than control group. Additionally, Thomas, (2006) ${ }^{(36)}$, noted that the application of sensory and motor stimulation on unconscious patients for more than one month improve the conscious level more significantly in study group than the control group. Likewise, Zhang, (2003) ${ }^{(11)}$ reported that the unconscious patients with head injury had a lower significant mean score of RCS scores post application of multimodal stimulation after 2 weeks.

The present study showed that the total mean score of Sensory Modality Assessment and Rehabilitation Technique (SMART) of the study group was increased more significantly after application of coma arousal technique throughout periods of study. This finding can be explained by Kalani et al., (2016) (26) that the coma arousal stimulation technique promotes brain organization by stimulating the reticular activating system through the sensory information received from 5 senses. Puggina et al., (2012) ${ }^{(37)}$, describe that the stimulation program improves secretion of neurotransmitters as 3methoxy; 4hydroxyphenylglycol levels which promotes brain recovery. This result was supported with Christakou et al., (2013) ${ }^{(21)}$ who concluded that the mean average scores of SMART for all sensory modalities in study group were significantly higher after application of coma arousal stimulation technique. In the same line, Wijdicks, (2006) ${ }^{(38)}$ noticed that the unconscious patients who exposed to stimulation program provided by the family and nurse had a significant recovery of sensory and motor function compared to control group. Moreover, Devlin et al., (1999) ${ }^{(39)}$ showed that an improvement scores of the motor, tactile, visual and auditory modalities after application of stimulation program for patients with head injury after 2weeks. In addition, Hassan et al., (2010) ${ }^{(24)}$ found that the unconscious patients were started to have tactile, auditory and motor responses on days 10-15 and noticed that the visual responses were begun after 20-25 days. Nevertheless, this result was contradicted with the result of Karma and Rawat (2006) ${ }^{(40)}$ who reported that the application of sensory stimulation on adult patient with traumatic brain injury didn't improve of sensory function.

Comparison of total mean scores regarding Motor Activity Assessment Scale (MAAS) among study and control groups throughout study period showed that patients' sedation in study group was significantly in more appropriate level after application of coma arousal technique than control group at $4^{\text {th }}$ and $6^{\text {th }}$ week of the study. Moreover, the current study revealed that patients in the study group who received coma arousal technique tended to "stay" in MAAS level 2-3 (calm, cooperative and responsive to touch) than patients in the control group who seemed to be more restlessness with deeper sedation level according to MAAS throughout the study period. This could be attributed to the soothing effect of caring touch through using tactile sensory modality that is involved in the coma arousal technique. It is documented that touch triggers a cascade of healing chemical responses including a decrease in stress hormones and an increase in serotonin and dopamine levels. The shift in these bio-chemicals has been proven to decrease anxiety, depression, hyperactivity and in attention ((Mandeep et al., 2013) ${ }^{(30)}$. Additionally, touch has been shown to increase the immune system's cytotoxic capacity, thereby helping our body maintain its defenses against pathogens (Corner et al., 2012) ${ }^{(20)}$. This may explain why patients in the study group displayed more comfort behaviors as measured by MASS than the control group.

Concerning secondary outcomes after application of coma arousal technique for the study group, the results of the current study were found that the study group had shorter length of stay in ICU compared to control group with a significant difference among both groups. This may be due to an improvement of conscious level that reflected on patient general function outcomes. This finding was in line with El-said, $(2011)^{(28)}$, who stated that the study group who participate in stimulation program had a short length of stay in intensive care unit. Moreover, Thomas, (2006) ${ }^{(36)}$ found that patients in the study group who engaged in sensory stimuli had short hospitalization period. Also, the data of the current study showed that there was a significant decrease in mean duration of mechanical ventilation for patients in the study group as compared with patients of the control group. This could be attributed to higher mental functions that were reflected on patient's ability to protect airway and maintain spontaneous breathing. This supported by Goudarzi et al., (2010) ${ }^{(32)}$ who reported that patient's level of consciousness affects the duration of mechanical ventilation, as high level of consciousness was accompanied with a decreased duration of mechanical ventilation. 


\section{Conclusion}

Based on the present study results, it can be concluded that application of coma arousal technique had effects on improvement the level of consciousness and sensory and motor modalities associated with a decreased incidence of physiological parameters adverse events (tachycardia, hypertension, hypervolemia, tachypnea, desaturation and hyperglycemia). Moreover, patients who received coma arousal technique tended to stay calm, cooperative and responsive to touch. In addition, it was effective in decreasing duration the length of ICU stay and duration of mechanical ventilation. Therefore, the study hypothesis that the unconscious patients who will subjected to coma arousal technique (study group) will be expected to improve consciousness, will have a significant lower incidence of serious physiological parameters adverse events, with a shorter duration of mechanical ventilation and length of ICU stay compared to (control group) patients who will not subject to coma arousal technique, was justified.

\section{Recommendations for Practice and Research}

Based on results of the current research, the following suggestions for future research and practice are proposed:

1. Critical care nurses should be incorporated coma arousal into a nurse's daily routine in the care of unconscious patients.

2. Practical workshops on coma arousal technique with unconscious patients are deemed necessary as they will have a positive impact on the ICU nurses caring for these patients.

3. Family members should be involved in an implementation of coma arousal technique to promote recovery and provide inner peace for the unconscious patients.

4. The current study findings need to be further validated through studies with larger sample sizes.

5. Future research related to application of coma arousal technique could focus on performing long-term follow-up to compare cognitive and functional abilities outcomes in unconscious patients.

\section{References}

[1]. Black JM, Hawks JH. Medical Surgical Nursing. 8th ed. Philadelphia: Saunders; 2009. P. 1792-3.

[2]. Popescu C1, Anghelescu A1, Daia C1 and Onose G1. Actual data on epidemiological evolution and prevention endeavours regarding traumatic brain injury Med Life J. 2015;8(3):272-7.

[3]. Mclean M, Ruff S, Graber p and Bucher L. Medical Surgical Nursing: Assessment and Management of Clinical Problems. 8thed. Philadelphia: Mosby \& Elsevier; 2011; 483,507.

[4]. Pornnipa U, Chanokporn J and Surachai K. Effects of the sensory stimulation program on recovery in unconscious patients with traumatic brain injury. Journal of Neuroscience Nursing 2009; 41 (3):501-9.

[5]. Oh, H and Seo W. Sensory stimulation programme to improve recovery in comatose patients. Journal of Clinical Nursing, 2003.12 ;( 3) 394-4.

[6]. Doman G, Wilkinson R, Mihai D, Pelligra R. The effect of intense multi-sensory stimulation on coma arousal and recovery. Neuro psych rehab 2007 oct 24; 3(2):203-12.

[7]. Bowen A, Knapp P, Gillespie D and Vail A. Non-pharmacological interventions for perceptual disorders following stroke and other adult, acquired, non-progressive brain injury. Cochrane Database of Systematic Reviews.2011;43(4):5-50.

[8]. Othman SY. Effect of implementing weaning guidelines on clinical outcomes among mechanically ventilated patients. Doctor thesis. Faculty of Nursing, University of Alexandria. Egypt; 2008.

[9]. World Health Organization. Violence and injury prevention and disability (VIP) 2011.Available at: www.who.int/violence injury prevention injury/ burns. Retrieved on 4/10/2015.

[10]. Zasler N, Katz D, Zafonte R. Brain Injury Medicine: Principles and Practice.NewYork, Demos. Com; 2007; 937-38.

[11]. Zhang Y. Real-time analysis of physiological data and development of alarm algorithms for patient monitoring in the intensive care unit. Master thesis. Faculty of Engineering. Massachusetts Institute of Technology; 2003.

[12]. American Medical Empire Blue Cross and Blue Shield Association. Sensory stimulation for coma patients, June 2009. Avialable at https://www.empireblue.com/medicalpolicies/policies/mp.

[13]. Tolle $\mathbf{P}$ and Reimer M. Do we need stimulation programs as a part of nursing care for patients in "persistent vegetative state?" A conceptual analysis. 2003; 25(2): 20-6.

[14]. Baker J. Coma Arousal Theory and Practical Considerations. [Online]. 2010 Available at: http://www.comacare.com/cgibin/giga.cgi?cmd=cause_dir_news_item\&cause_id=1784\&news_id=84750\&cat_id=0. Retrieved on Oct 31, 2012.

[15]. Wood RL. Critical analysis of the concept of sensory stimulation for patients in vegetative states. Brain Injury, 1991, 5(4): 401409.

[16]. Devlin JW, Boleski G, Mlynarek M, etal. Motor Activity Assessment Scale: a valid and reliable sedation scale for use with mechanically ventilated patients in an adult surgical intensive care unit. Crit Care Med. 1999; 27: 1271-75. http://dx.doi.org/10.1097/00003 246-199907000-00008

[17]. Barbarito D. Health and Physical Assessment in Nursing, London, Pearson Co, 2007; 123-133.

[18]. Gill-Thwaites H, Munday R. The Sensory Modality Assessment and Rehabilitation Technique (SMART): a valid and reliable assessment for vegetative state and minimally conscious state patients. Brain Inj. 2004 Dec;18(12):1255-69.

[19]. McNett M. A review of the predictive ability of Glasgow Coma Scale scores in head-injured patients. J NeurosciNurs. 2007; 39(2):68-75.

[20]. Corner EJ, Wood H and Englebretsen C.: The Chelsea Critical Care Physical Assessment Tool: validation of an innovative new tool to measure physical morbidity in the general adult critical care population; an observational proof-of-concept pilot study. Physiotherapy J, 2012; 99 (1):33-7.

[21]. Christakou A, Papadopoulos E, Patsaki I and Sidiras G. Functional Assessment Scales in a General Intensive Care Unit. A review, hospital chronicles 2013; 8(4): 164-70. 
[22]. Petrie A and Sabin C. Medical Statistics at a Glance. 2nd ed., Blackwell Publishing, 2005.

[23]. Amir M, Alotaibi A, Albaradie R and Elrazkey G. Effect of supine versus semi-fowler's positions on hemodynamic stability of patients with head injury. World journal of Pharmaceutical research, 2015; 14 (4): 1559-69.

[24]. Hassan N, El Kelany R, Emara A, Amer A. Pattern of craniofacial injuries in patients admitted to Tanta University Hospital Egypt. Forensic and legal medicine Journal 2010; 17(1):26-32.

[25]. Mohamed Z. Impact of Sensory Stimulations Provided to Head Injured Patients Upon Their Cognitive Response in Shebin El-Kom University Hospital. Unpublished Doctorate Dissertation. Faculty of Nursing. University of Menofia, 2004

[26]. Kalani Z, Pourkermanian $\mathbf{P}$ and Alimohammadi N. The Effect of Family Guided Visits on the Level of Consciousness in Traumatic Brain Injury. Biology and today world J. 2016;5 (5) 86-90.

[27]. Megha M, Harpreet $\mathbf{S}$ and Nayeem $\mathbf{Z}$. Effect of frequency of multimodal coma stimulation on the consciousness levels of traumatic brain injury comatose patients. Brain Inj. 2013; 27:570-7.

[28]. El-said M. The effect of implementing a structured stimulation program on altered consciousness of critically ill patients at Mansoura University. Unpublished Doctorate Dissertation. Faculty of Nursing. University of Mansoura, 2011.

[29]. Moattari M, Shirazi F, Sharifi N and Zareh N. Effects of a Sensory Stimulation by Nurses and Families on Level of Cognitive Function, and Basic Cognitive Sensory Recovery of Comatose Patients with Severe Traumatic Brain Injury: A Randomized Control Trial. Trauma Monthly J.2016; 21(1):2-10.

[30]. Mandeep K, Chitkara N, Goel S and Sood S. Traumatic head injury: Early intervention by coma arousal therapy. The Indian Journal of Neurotrauma; 2013; 10(1):13-8.

[31]. Hashmi M. Evaluating impact of the Chelsea critical care physical assessment (CPAx) tool on rehabilitation in critical care and feasibility in practice. J Rehabil Med 2012; 44: 505-11.

[32]. Goudarzi F, Basampoor S, Zakeri-Moghadam M, et al. Changes in level of consciousness during auditory stimulation by familiar voice in comatose patients. Iran Journal of Nursing. 2010; 23(63): 43-50.

[33]. Simões J, Jesus L, VoegeliD, etal. The effects of a caustic stimulation on comatose patients. In: Silva E (Eds) Comas and Syncope: Causes, Prevention and Treatment. New York: Nova Science; 2012. 1-31.

[34]. Happ MB, Garrett K, Thomas DD, et al. Nurse-patient communication interaction in the intensive care unit. American Journal of Critical Care. 2011; 20(2): e28-40. PMid:21362711http://dx.d oi.org/10.4037/ajcc2011433

[35]. Bickmore TW, Fernando R, Ring L, et al. Empathic Touch by Relational Agents. IEEE Transactions on Affective Computing. 2010; 1(1): 60-71. http://dx.doi.org/10.1109/T-AFFC.2010.4

[36]. Thomas D. A Study to assess the effectiveness of planned teaching program for nurses working in ICU of St. John's Medical College Hospital, Bangalore on communication to unconscious patients. Master thesis of medical surgical nursing. College of nursing, John's national academy of health science, Bangalore 2006.

[37]. Puggina A, Silva M, Schnakers C, et.al. Nursing care of patients with disorder of consciousness. Journal of neuroscience nursing. 2012; 44(3): 260-70. PMid:22955240http://dx.doi.org/10.1097/J NN.0b013e3182666407

[38]. Wijdicks EF. Clinical scales for comatose patients: The Glasgow Coma Scale in historical context and the new FOUR Score. Reviews in Neurological Disease. 2006; 3(3): 109-17. PMid:17047576

[39]. Devlin JW, Boleski G, Mlynarek M, etal. Motor Activity Assessment Scale: a valid and reliable sedation scale for use with mechanically ventilated patients in an adult surgical intensive care unit. Crit Care Med. 1999; 27: 1271-75. http://dx.doi.org/10.1097/00003 246-199907000-00008

[40]. Karma D, Rawat AK. Effect of stimulation in coma. Indian Pediatr. 2006; 43(10): 856-60. 